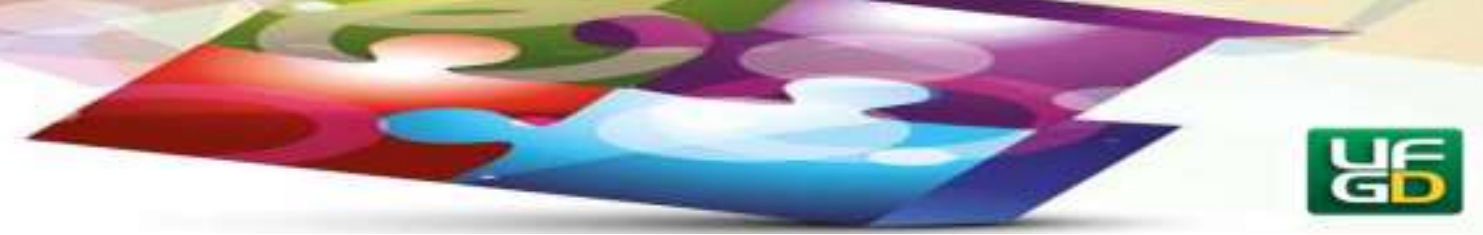

\title{
CAMINHOS PERCORRIDOS PELA EDUCAÇÃO PROFISSIONAL: O PRESCRITO E O VIVIDO
}

\author{
Joilson Silva de SOUSA ${ }^{1}$ \\ Alanderson Maxson Ferreira do NASCIMENTO ${ }^{2}$ \\ Avelino Aldo de LIMA NETO ${ }^{3}$
}

O livro organizado por Antônia de Abreu Sousa e Elenice Gomes de Oliveira é uma coletânea de textos com contribuições teórico-empíricas de integrantes do Núcleo de Pesquisas em Educação Profissional (NUPEP) da Universidade Federal do Ceará e demais pesquisadores de instituições de ensino da Rede Federal de Educação Profissional Científica e Tecnológica.

O campo conceitual do Trabalho e da Educação, já tradicional do ponto de vista epistemológico, constituindo-se inclusive em Grupo de Trabalho da ANPED (GT-09), tem papel central no desenvolvimento dos escritos. Para além dessa influência primeira, notam-se nos textos as reverberações ligadas a fatores sociais, pedagógicos e financeiros, especificamente às propostas governamentais de formação dos jovens discentes do ensino médio (enquanto etapa da Educação Básica) e a integração entre a formação geral e a formação profissional.

A obra resenhada, possui oito capítulos de análises temáticas como a reestruturação produtiva, novos paradigmas de qualificação para o trabalho, a educação profissional, as influências de organismos internacionais como o Banco Mundial, a Teoria do Capital Humano, bem como as mudanças no Ensino Médio de Nível Técnico.

No primeiro capítulo, intitulado Empregabilidade, Competências e Desqualificação dos Trabalhadores: a dança das palavras sobre o solo real das Transformações produtivas, Enéas Neto apresenta, a partir de uma vertente historiográfica alinhada à teoria de análise do

\footnotetext{
${ }^{1}$ Doutorando em Educação pelo Programa de Pós-graduação em Educação Profissional do Instituto Federal de Educação, Ciência e Tecnologia do Rio Grande do Norte. Professor Auxiliar do Departamento de Educação da Universidade do Estado do Rio Grande do Norte - UERN no Campus Avançado de Assu-RN. E-mail: joilsondesousa@hotmail.com

${ }^{2}$ Mestrando do Programa de Pós Graduação em Educação Profissional do Instituto Federal de Educação, Ciência e Tecnologia do Rio Grande do Norte/IFRN. Professor do Instituto Federal de Educação, Ciência e Tecnologia do Sertão Pernambucano. Licenciado e Bacharelado em Música pela Escola de Música da Universidade Federal do Rio Grande do Norte (EMUFRN). E-mail: alandersonclarinetista@gmail.com

${ }^{3}$ Doutor em Educação pela Université Paul Valéry - Montpellier III e pela Universidade Federal do Rio Grande do Norte, mestre em Filosofia pela Universidade Federal do Rio Grande do Norte e licenciado em Filosofia pelo Instituto Salesiano de Filosofia. Professor do Instituto Federal de Educação, Ciência e Tecnologia do Rio Grande do Norte e dos Programas de Pós-Graduação em Educação Profissional (PPGEP/IFRN) e em Educação (PPGED/UFRN).E-mail: ave.neto@ hotmail.com
} 


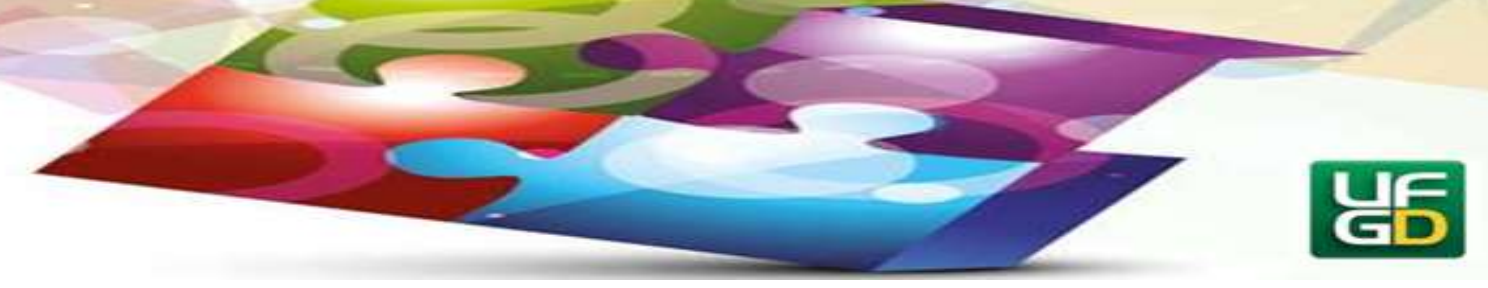

materialismo histórico-dialético, os debates dos últimos vinte anos sobre as transformações dos modelos de produção, as novas formas de organização do trabalho e as reverberações no âmbito social causadas pela tecnologia. O autor argumenta sobre o fato de o mundo ter "ingerido" formas de expressão oriundas dos EUA e da Europa, o que parece ter levado o modelo político do Estado de bem-estar social à falência. Isso ocorreu devido ao neoliberalismo e ao movimento cultural do pós-modernismo, denominado pelo autor de "novo paradigma social".

Tais influências vêm ganhando espaço no cenário político graças à sua roupagem "pseudoprogressista", permitindo-lhes encontrar espaços em campos do conhecimento voltados para o estudo do trabalho e da educação. Por trazer no texto uma enorme erudição na escrita científica, é necessária uma leitura atenta, sobretudo no que concerne à argumentação acerca da globalização. Nessa ótica, a reestruturação produtiva, o avanço neoliberal e a globalização são fatores determinantes para a manutenção do capital e influenciam a educação que "[...] é acenada como ferramenta dessas batalhas de uma guerra globalizada" (p. 33). No interior dessa esfera econômica a educação é utilizada como projeto de desenvolvimento do capital onde a qualificação e a desqualificação profissional operam enquanto parâmetros para a empregabilidade no panorama tecnológico atual.

No segundo capítulo, intitulado Do Modelo Fordista às Teorias da Reestruturação Produtiva: os impactos sobre a cidadania e a formação humana, Josania Portela enfatiza o conceito de "cidadania social". Partindo, inicialmente, dos pressupostos liberais ancorados nas ideias de Marshall (1967), ela estabelece que o conceito de cidadania é composto através de três direitos, a saber: civis, políticos e sociais. Eles facultam aos sujeitos serem "qualificados como cidadãos do Estado" (p. 43). A autora descreve ainda, a classe social como um dos desafios para o desenvolvimento da cidadania, o que é enfatizado no âmbito científico pelos dados da desigualdade social.

No cerne do artigo, a autora assevera que o modelo fordista possibilitou a cidadania social, no qual a profissionalização da força de trabalho alinhou-se a essa ideia de que no capitalismo, a educação escolar é utilizada como forma de contenção dos problemas sociais, e que após a Segunda Revolução Industrial a escolarização é fator preponderante na qualificação dos trabalhadores. Nessa ótica, apresenta-se a Teoria do Capital Humano, elaborada sistematicamente na década de 1950 e que segue atuante durante o predomínio do modelo 


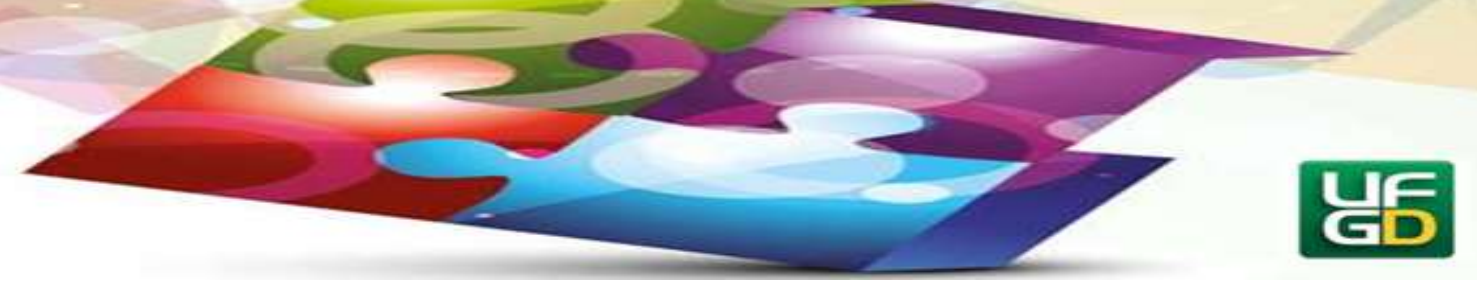

taylorista-fordista de produção até o início da década de 1970, quando este entra em saturação e uma nova fase de sociabilidade estabelece a reestruturação produtiva.

A autora sistematiza a ideia de que a teoria anteriormente mencionada ganha uma nova forma, "revitalizada", a partir dos trabalhos de Gary Becker. Prêmio Nobel de Economia, esse estudioso buscou explicar e justificar as diferenças salariais dos trabalhadores ao enfatizar que a formação destes últimos (em maior grau) aumentaria a produtividade. Sendo assim, o indivíduo deve investir em seu "capital pessoal”, na sua autoformação.

No terceiro capítulo, cujo título é O Novo Paradigma Técnico-Produtivo e a Qualificação do Trabalhador, de autoria de Francisca das Chagas Silva Lima, busca-se compreender a educação profissional na ótica do vínculo entre trabalho e educação. As relações sociais provenientes do capitalismo contemporâneo são o campo do estudo da autora, que estabelece como referenciais o universo laboral e as demandas educativas que deste resultam. Para ela, as novas formas de organização do trabalho, as mudanças de mercado e o advento da microeletrônica (informatização), tornam possíveis uma valorização da qualificação dos trabalhadores. Nesse sentido, a educação profissional tem papel decisivo. Ressalta, igualmente, que a produtividade no novo padrão tecnológico e organizacional tem gerado redução do tempo de trabalho e consequentemente a expulsão de grande parte da classe trabalhadora do mercado.

Nessa direção, a autora destaca o papel da qualificação profissional e enfatiza que, no contexto do atual modelo capitalista de produção, uma determinada formação tem não apenas valor de requisito para ocupar uma função, mas sobretudo, valor que a mercadoria assume. Postulamos que a autora poderia ter enfatizado como se gestou e desenvolveu essa nova demanda da classe trabalhadora não apenas no cenário global, mas sobretudo no Brasil.

No quarto capítulo, nomeado de Novos Caminhos na Educação Profissional Brasileira?, Elenice Gomes de Oliveira aponta o processo político desencadeador de mudanças na Educação Profissional, tanto ao Projeto de Lei n ${ }^{\circ}$ 1.603, de 1997, de mudanças drásticas na gestão e financiamento da EP, como o Decreto n ${ }^{\circ} 2.208$, de 1997 do ex-presidente Fernando Henrique Cardoso, que de forma impositiva (via decreto), promoveu uma reforma na Educação Profissional, o que para a autora, se alinha com a proposta neoliberal de governo e o cenário global capitalista, que utiliza categorias como: competência, flexibilidade e empregabilidade.

Por fim, a autora sublinha que muitos movimentos foram capitaneados por entidades representativas como CUT, ANPED, ANFOPE, SINASEFE e outros, o que culminou com o 


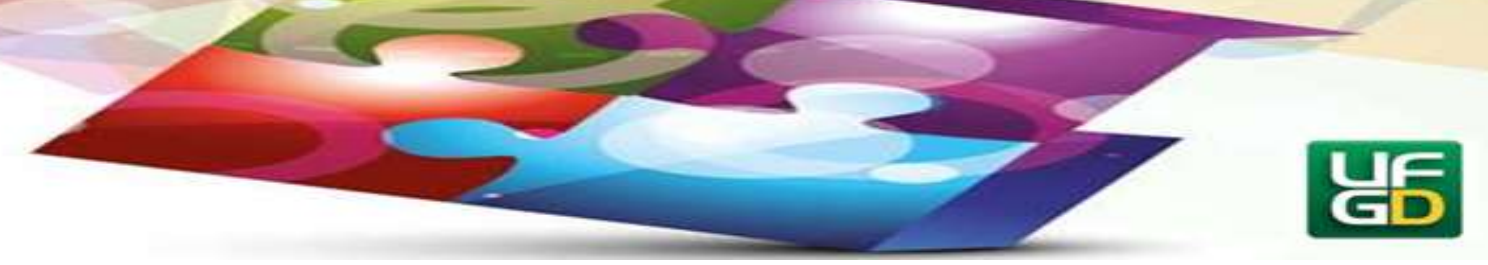

Seminário Nacional de Educação Profissional, promovido pelo Ministério da Educação no ano de 2003. Nesse evento, foi defendida a necessidade de revogação do Decreto $n^{\circ} 2.208$, de 1997. Assim, em 2004, foi aprovado o Decreto ${ }^{\circ}$ 5.154, que revoga em parte o Decreto $\mathrm{n}^{\circ} 2.208$, de 1997. No entanto, para a autora, o Decreto de 2004 traz permanências e rupturas com a legislação anterior, mantendo bases para uma formação humana integral, sem perder o viés da educação produtivista.

As recomendações do Banco Mundial para a educação profissional e o vigor da teoria do capital humano no contexto do neoliberalismo é o título do quinto capítulo, de autoria de Antônia de Abreu Sousa. A pesquisadora discute o financiamento da educação profissional e sua relação com as políticas do Banco Mundial. Para tanto, inicia o capítulo revisitando a obra O caminho da servidão, de Friedrich Hayek, e referencia-o como um marco no surgimento do neoliberalismo, modelo de governabilidade que, como sabemos, tem como principal característica o combate à intervenção do Estado sobre a economia, cabendo ao mercado ser a instituição reguladora.

Segundo a autora, o Banco Mundial é o principal financiador de projetos no setor educacional no Brasil. Essa realidade interfere diretamente no campo das políticas educacionais, pois enquanto tomador de empréstimos o país precisa adotar as diretrizes impostas pela referida agência financiadora. Assim, se referindo às políticas para a educação do Banco Mundial, Antônia Sousa relata que, segundo o banco, a atuação do governo deveria se voltar para o incremento do nível fundamental de ensino, ficando as escolas profissionalizantes sob o gerenciamento do setor privado, pois teria uma relação intrínseca com o mercado de trabalho. Ela traz ainda pesquisas e estudos que consideram a educação dentro de um paradigma de função produtiva, orientadas pela já supracitada Teoria do Capital Humano (TCH). Essas pesquisas reforçam que o ensino fundamental apresenta "rentabilidade social mais elevada" e, assim, recomendam o investimento de gastos públicos nessa etapa educativa.

No tocante ao ensino profissionalizante, essa teoria postula que a separação da formação técnica da formação geral traria melhoras para a classe empresarial, já que esta última poderia ajustar a oferta de cursos às necessidades do mercado. Essas orientações foram percebidas no Brasil na década de 1990 com o Decreto n 2.208 , de 1997, que separou o ensino médio do técnico. 


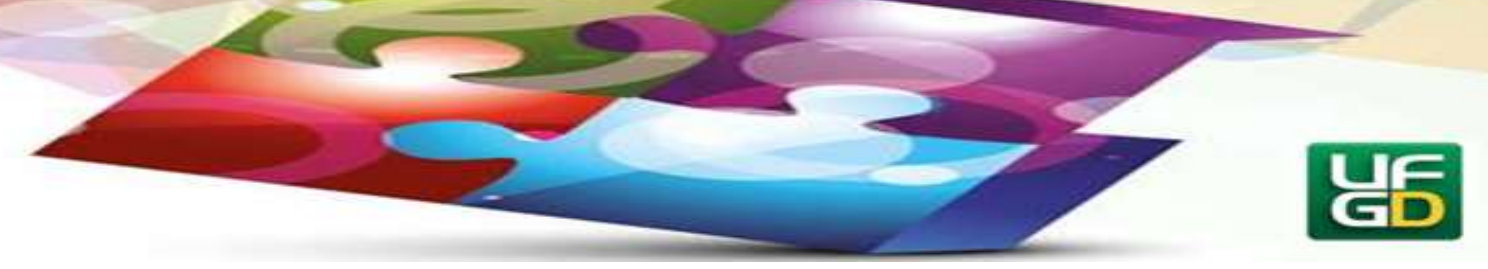

O sexto capítulo, assinado por Lélia Cristina Silveira de Moraes, tem como título $A$ formação profissional em nível técnico no contexto da política educacional dos anos 1990 compreendendo os seus impactos a partir dos sujeitos que a vivenciam. Nele, há uma análise dos resultados da política educacional para o ensino profissionalizante da década citada no título, destacando as contradições presentes na organização curricular dos novos cursos. O lócus da pesquisa foi o Curso Técnico em Edificações oferecido pelo Centro Federal de Educação Tecnológica do Maranhão.

Ao discutir sobre as exigências de formação do trabalhador e a lógica de reconfiguração do capitalismo, Lélia afirma que as lógicas deste sistema no tocante à relação de trabalho como mais-valia, exploração e expropriação do saber do trabalhador propiciaram também uma reconfiguração na pedagogia de formação da classe operária, passando a oferecer nesta formação a capacidade de abstração, a polivalência, a flexibilidade, a criatividade e a participação. Ao trazer a voz dos sujeitos no tocante à reforma da Educação Profissional e as novas orientações curriculares para os cursos técnicos que estavam sob a égide do Decreto $\mathrm{n}^{\circ}$ 2.208, de 1997, a autora mostra a visão dos jovens e das empresas.

Enquanto os jovens acreditavam que a profissionalização era uma possibilidade de ingresso no mercado de trabalho, as empresas atribuíam o desemprego ao despreparo da mão de obra. Segundo a investigadora, esse despreparo apontado pelos empregadores poderia ter uma relação com o currículo da formação profissional em vigência, que separava a formação técnica da cultura geral. Os alunos precisavam articular a formação recebida em uma determinada instituição (onde estavam matriculados no ensino regular) à outra (na qual cursavam o técnico). A autora defende que a integração possibilitada pelo Decreto $\mathrm{n}^{\circ} 5.154$, de 2004, foi um caminho para melhorar a formação, mas acredita que tal integração deve ser pensada em um contexto mais amplo, no qual sejam incorporadas, entre outras questões centrais, a concepção de conhecimento, a relação ciência e tecnologia, as condições objetivas de trabalho da escola, a infraestrutura pedagógica e administrativa, além da realidade socioeconômica e cultural dos alunos, tornando viva e explícita a função social da escola como mediadora da práxis social.

Tendo como autora Izaura Silva, o sétimo capítulo - A reforma da Educação Profissional de Nível Técnico: uma análise da fase preliminar - circunscreve-se enquanto pesquisa exploratória, realizada no Centro Federal de Educação Tecnológica do Maranhão - 


\section{HORIZONTES - REVISTA DE EDUCAÇÃO}

Unidade descentralizada (UNED) de Imperatriz, entre os anos de 1998 e 1999. No manuscrito, a autora analisa as reformas vigentes no currículo da Educação Profissional, dividindo-as em duas etapas. Na primeira, acontece a aplicação do exposto no Decreto n $^{\circ} 2.208$, de 1997 até 1999; na segunda, após a publicação das Diretrizes Curriculares Nacionais para a Educação Profissional de Nível Técnico (Parecer no 16/99 e a Resolução CNE/CEB 04, de 1999), materializa-se a institucionalização do currículo implementado a partir do ano 2000.

Segundo a autora, essas mudanças aconteceram como forma de atender as transformações econômicas, políticas e sociais da década de 1990. Como parte importante dessas políticas educacionais, o Decreto n 2.208, de 1997, cria o que Luís Antônio Cunha chamou de sistema paralelo de ensino. A partir desse decreto, tem início uma nova modalidade de curso intitulado pós-médio, que aumentava a duração do curso técnico de quatro para cinco anos, pois era necessário concluir os três anos do ensino médio e dar continuidade a uma formação técnica de dois anos. Conforme relata a autora, houve uma diminuição na procura pelos cursos técnicos e um aumento na evasão, pois os alunos não conseguiam realizar a concomitância dos cursos devido dentre outros fatores, a indisponibilidade de dois turnos livres para os estudos.

Izaura Silva sustenta que essa característica de proposta curricular não contribui para a formação integral do cidadão, tendo apenas a preocupação de suprir as necessidades do mercado de trabalho. A autora relata que a extinção do ensino integrado fez com que os alunos das escolas públicas perdessem a chance de cursar um ensino gratuito, de qualidade, que lhes propiciaria uma profissão valorizada no mercado de trabalho e a possibilidade de ingressar em uma universidade pública. Na finalização do capítulo, Izaura sublinha que esta primeira fase da reforma beneficiou o setor produtivo, pois ofereceu mão-de-obra barata, prejudicando, assim, a educação profissional do país e à classe trabalhadora.

O oitavo e último capítulo, intitulado $O$ Ensino Médio e a Formação do Trabalhador: competências para quem e para quê?, tem como autores Maria José Pires Barros Cardoso e Enéas de Araújo Arrais Neto. Ao iniciar a discussão sobre o ensino médio e a formação do trabalhador, os autores asseveram que o projeto burguês procura educar o trabalhador de acordo com as necessidades de valorização do capital e da reprodução da força de trabalho como mercadoria. 


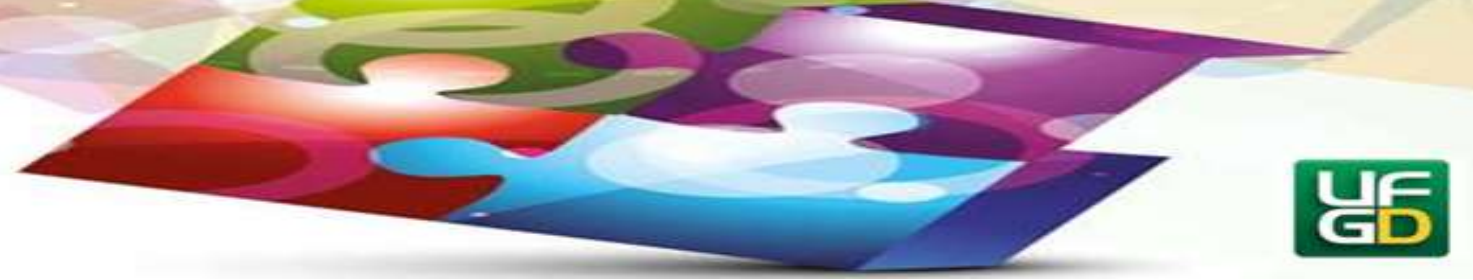

Nessa perspectiva, os autores apresentam três enfoques às qualidades requeridas aos trabalhadores. O primeiro é a desqualificação progressiva, segundo a qual quanto maior é o desenvolvimento tecnológico, maior é a degradação da execução direta. O segundo sustenta que o desenvolvimento tecnológico leva ao predomínio de tarefas mais complexas, exigindo, assim, uma elevação da qualificação da força de trabalho. O terceiro, por fim, aponta para o caráter complexo e contraditório de mudanças na qualificação, para o movimento constante de desqualificação e qualificação.

Nesse cenário, os discursos empresarial e governamental sustentarão que compete à educação preparar os indivíduos para a empregabilidade, desenvolvendo as competências enfatizadas pelo mundo do trabalho. Nesse sentido, observa-se uma centralidade à Educação Básica no Brasil, que passa a ser vista como prioridade, uma vez que sem ela não seria possível a produção do saber necessário ao processo produtivo, ou seja, a preparação para a empregabilidade. Conforme os autores, esse fato é tratado na própria Lei $n^{\circ} 9.394$, de 1996, que direciona a educação básica para a elaboração de competências cujo objetivo era a preparação básica para o trabalho.

Ressaltamos que essa obra colabora para a produção do conhecimento científico sobre a Educação Profissional. A leitura da obra é um convite interessante a professores das diversas licenciaturas, que nos cursos de graduação têm debates incipientes acerca da Educação Profissional. Também aos professores atuantes na Educação Profissional, mas não-licenciados, o material aqui resenhado se apresenta como de extrema relevância, posto que indica de maneira didática e aprofundada o conjunto de fenômenos que construiu a Educação Profissional como ela se encontra hoje. Esses bacharéis, agora docentes, podem, dessa maneira, se apropriar melhor da realidade educativa da qual fazem parte.

\section{Referência}

SOUSA, Antônia de Abreu; OLIVEIRA, Elenice Gomes de. (Org.). Educação Profissional: análise contextualizada. Fortaleza: Edições UFC, 2014, 186 p.

Enviado: 29/02/2020

Aceito: 09/06/2020 